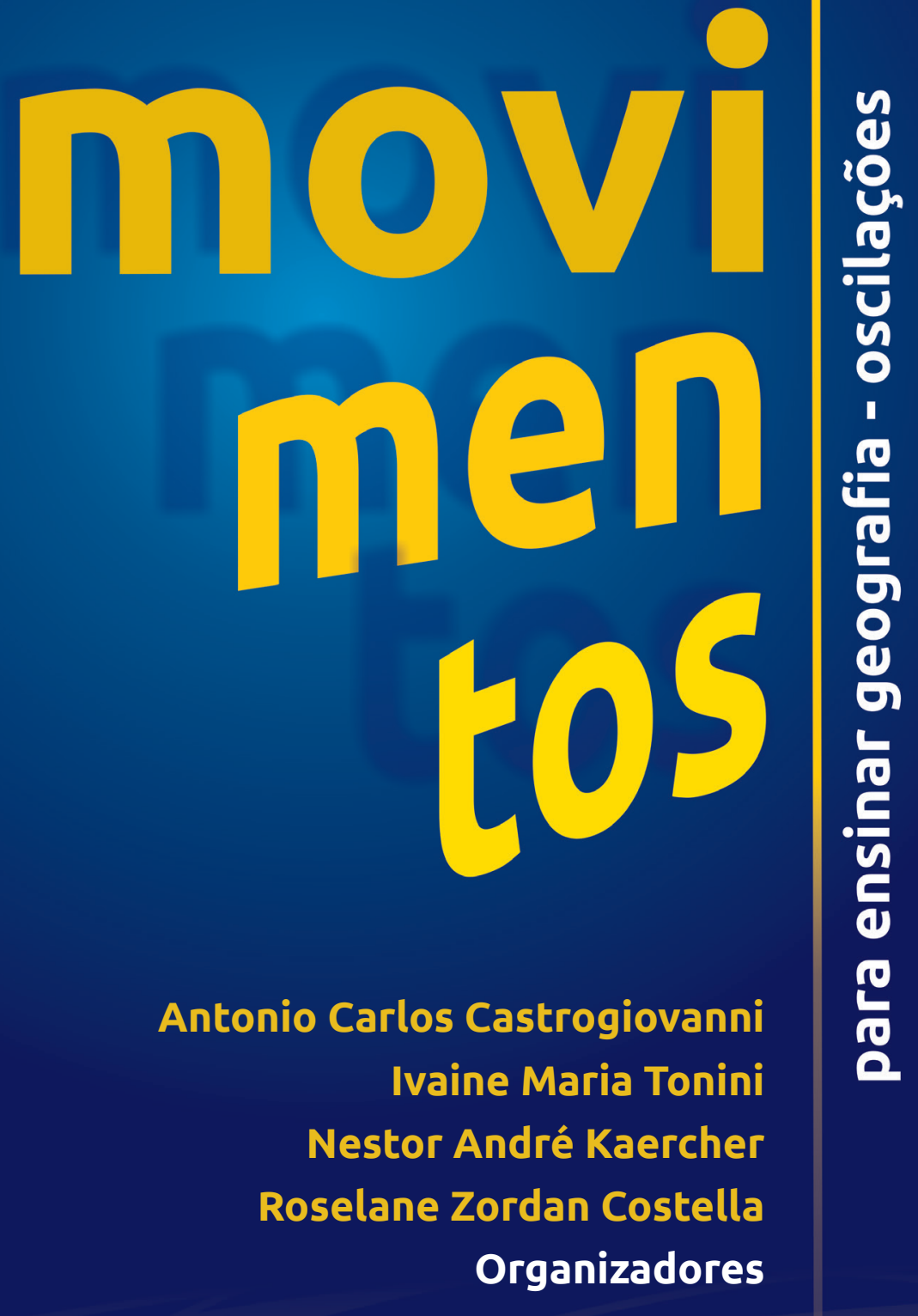




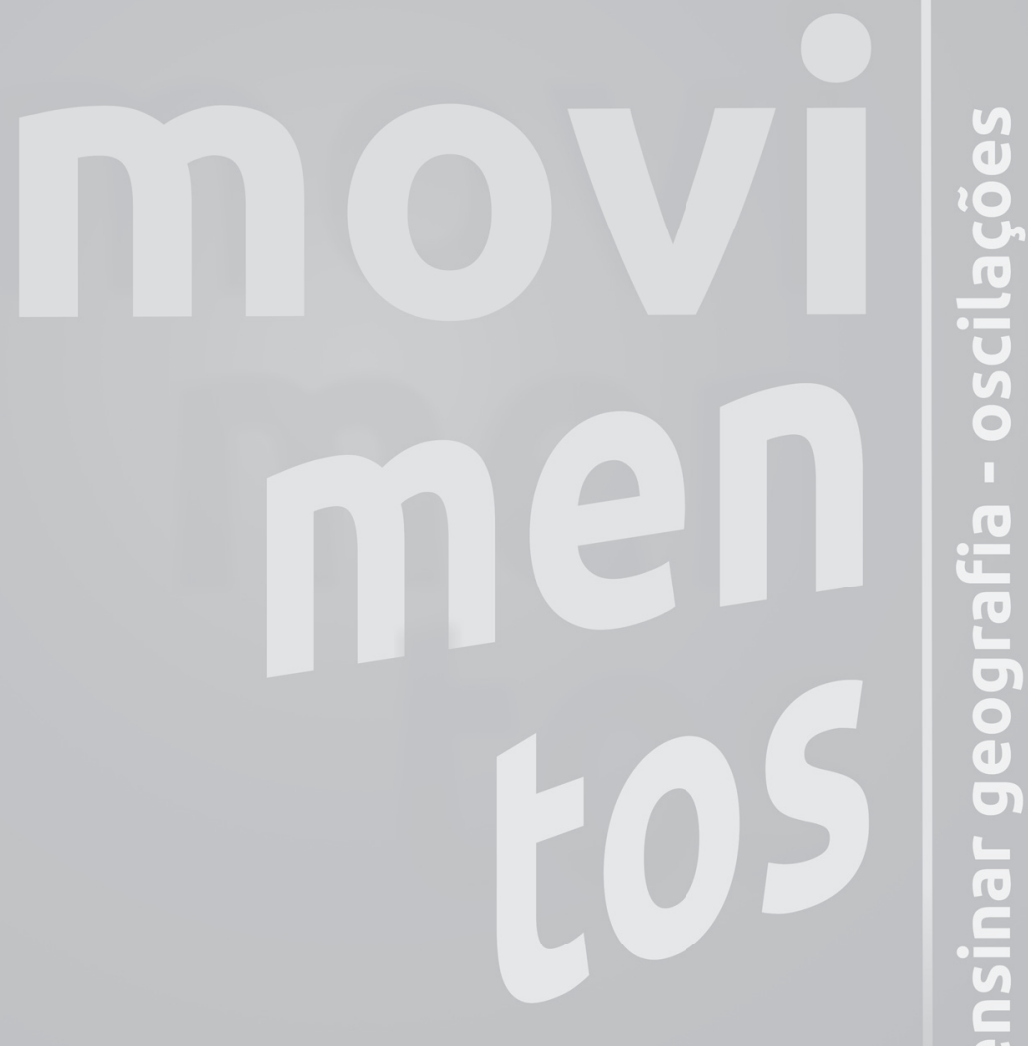

Antonio Carlos Castrogiovanni Ivaine Maria Tonini Nestor André Kaercher Roselane Zordan Costella Organizadores 
๑) 2016 - Autores

\section{Revisão}

Geordana Cavalheiro

Paulo de Toledo

\section{Capa}

Simone Rocha da Conceição

\section{Projeto gráfico e diagramação}

Ronaldo Machado | Letra1

\section{Impressão}

Gráfica da UFRGS

DADOS INTERNACIONAIS DE PUBLICAÇÃO

Bibliotecária Ketlen Stueber CRB: 10/2221

M935 Movimentos para ensinar Geografia - oscilações / organização de Antonio Carlos Castrogiovanni [et al.]. Porto Alegre: Editora Letra1, 2016.312p.

Outros organizadores: Ivaine Maria Tonini, Nestor André Kaercher e Roselane Zordan Costella.

ISBN 978-85-63800-24-4

\section{DOI 10.21826/9788563800244}

1. Geografia e práticas de ensino. 2. Alteridade e troca de conhecimento. 3. Abordagem inclusiva e dialógica. I. Castrogiovanni, Antonio Carlos. II. Tonini, Ivaine Maria. III. Kaercher, Nestor André. IV. Costella, Roselane Zordan. V. Título

\section{Disponível para download em}

http://www.lume.ufrgs.br/

www.editoraletra 1.com.br

CNPJ 12.062.268/0001-37

letra1@editoraletra1.com.br 


\title{
O jovem contemporâneo e a geografia escolar: tão perto e tão longe
}

\author{
Victor Hugo Nedel Oliveira \\ Nestor André Kaercher
}

\author{
In: CASTROGIOVANNI, A. C.; TONINI, I. M.; \\ KAERCHER, N. A.; COSTELLA, R. Z. (Orgs.). \\ Movimentos para ensinar geografia - oscilações. \\ Porto Alegre: Editora Letra1, 2016, p. 117-132 \\ DOI $10.21826 / 9788563800244$ p $117-132$
}

\section{Resumo}

O jovem contemporâneo vem surpreendendo a sociedade nos mais diferentes setores. Este artigo trata das culturas juvenis no âmbito escolar e suas relações com o ensino da Geografia. Objetivamos identificar os sentidos que jovens do ensino médio atribuem ao ensino desta disciplina. O referencial teórico utilizado buscou colocar em diálogo as duas grandes linhas de investigação: as culturas juvenis e o ensino de Geografia. Para atingir os objetivos propostos, montamos um questionário - sobre as relações dos sujeitos-jovens entrevistados com a Geografia escolar - que foi aplicado em três turmas de terceiro ano do ensino médio de uma escola pública estadual em Porto Alegre (RS). Os resultados da pesquisa indicam que o jovem-aluno vincula muito fortemente aos temas físicos da ciência, ao citar exemplos como localização geográfica e fusos horários. Há o questionamento, então, sobre a condução das aulas de Geografia, no ensino básico, a saber, se as mesmas dão conta do conceito pleno do espaço geográfico, no sentido de trabalhar as temáticas físicas, mas também as humanas da ciência. Percebemos que há relação direta entre as práticas juvenis e possíveis temas a serem trabalhados na aula de Geografia. Há muito que se avançar 
neste tipo de pesquisa, uma vez que tratamos além dos objetos já previstos, de nossa prática docente.

Palavras-chave: Jovens. Juventude. Ensino. Geografia.

\section{Resumen}

El jóven contemporáneo viene sorprendendo la sociedad en muchos sectores diferentes. Esta investigación se ocupa de las culturas juveniles en el entorno escolar y su relación con la enseñanza de la geografía. Este estudio tuvo como objetivo identificar los significados que atribuyen a los estudiantes de la escuela secundaria a la enseñanza de la Geografía. El marco teórico trató de poner en las dos principales líneas de diálogo desta investigación: culturas juveniles y la enseñanza de la geografía. Para lograr los objetivos propuestos, se reunió una encuesta acerca de la relación del sujeto-jóven encuestados con la geografía, aplicada en tres clases de tercer grado de la escuela de secundaria de la red pública estadual en Porto Alegre (RS). Los resultados de la encuesta indican que el joven estudiante vincula muy fuertemente a los problemas físicos de la ciencia, citando ejemplos como ubicación y tiempo zonas geográficas. Está la cuestión, entonces, sobre la realización de clases de Geografía en la educación primaria, es decir, si se dan cuenta el concepto completo del espacio geográfico con el fin de trabajar los problemas físicos, sino también la ciencia humana. Se observó que existe una relación directa entre las prácticas de los jóvenes y los posibles temas que se trabaja en la clase de geografía. Hay mucho que avanzar en este tipo de investigación, ya que tratar, además de los objetos ya siempre en nuestra práctica docente.

Palabras-clave: Joven. Juventud.Enseñanza. Geografía.

\section{De ensino e de jovens contemporâneos}

Somos tão jovens? Ainda persiste, em nossa sociedade, a busca pela eterna beleza, a eterna juventude? E o sonho de beber o elixir mágico da juventude e não envelhecer mais? Por longos anos a juventude foi tema de debate dos gregos e seus sucessores. Atualmente, vemos os avanços das áreas médicas em postergar a velhice. As capas de revista, apresentando formas jovens e esculturais, formando um ideal de beleza quase utópico. Mas não é sobre esta juventude que este trabalho se dispõe a tratar.

Aqui, queremos discutir sobre essa fase que todos passamos: a juventude - que, por vezes se estende muito além do delimitado pela idade - e suas relações com a Geografia, enquanto disciplina escolar e, por consequência, formadora de cidadãos presentes e atuantes no mundo. Queremos ver mais de perto as diferentes culturas juvenis e como podem nos ajudar a docenciar no ensino da Geografia. 
Nesse caso, também entra em cena o papel da formação da Geografia, no sentido de discutir os temas atuais da sociedade brasileira com os alunos. CacciaBava e Costa (2004, p. 15) já afirmaram esse histórico da juventude brasileira, ao proferir que:

\begin{abstract}
[...] a formulação de uma primeira síntese da história da juventude brasileira permitiu-nos identificar um traço constante que caracteriza os grupos e movimentos de jovens: a ingenuidade e a honestidade. A exposição das motivações e intenções culturais e políticas apareceu como traço marcante da condição juvenil, que rejeitaria o maquiavelismo como forma de ser dominante. [grifo nosso].
\end{abstract}

Nesse sentido, cabe lembrar que rebeldia, inquietação e inconformidade fazem parte das culturas juvenis, não só nos tempos de outrora, mas também nos jovens contemporâneos que encontro em minhas salas de aula. $O$ fato é que muitas vezes, ao recebermos esses alunos, não há uma base conceitual clara e sólida, que já deveria ter sido trabalhada desde o ensino fundamental. Não quero aqui jogar a culpa para os professores dessa etapa formativa. O que se faz é a conclusão necessária de que, sem uma base clara para discussões em sala de aula, o professor pouco pode agir, devendo estar constantemente retomando os assuntos anteriores. Sobre essa temática da inconformidade com gerações anteriores ou com o momento atual estabelecido, outro autor muito conhecido e admirado nos estudos de culturas juvenis, Pais (2003, p.44), já nos aponta que “[...] as culturas juvenis definem-se por relativa oposição à cultura dominante das gerações mais velhas, como uma forma de 'resistência' à cultura da 'classe dominante', quando não mesmo a sua expressão linear”.

\title{
De jovens contemporâneos e de geografia escolar
}

Questionamos os sujeitos da pesquisa para responder a seguinte questão: Com relação à disciplina de Geografia, você pode dizer que: e com cinco afirmativas, a saber, já com as porcentagens de respostas:

a) gosta mais de Geografia do que qualquer outra disciplina - 6\%;

b) gosta de Geografia - 65\%;

c) é indiferente (nem gosta nem antipatiza) - 26\%;

d) não gosta de Geografia - 3\%;

e) detesta Geografia $0 \%$.

De posse desses dados, nos parece muito claro que os alunos, de maneira geral, possuem uma visão positiva em relação à disciplina de Geografia e que esta relação próxima se deu, a priori, pela influência de bons professores (que sabiam a matéria) ou por professores camaradas (que eram amigos da turma), conforme podemos observar no gráfico que segue. 
Sob essa ótica, entendemos que a primeira aproximação que o aluno tem em relação à disciplina de Geografia se dá através de seu professor e este dado apenas reforça a tese de que é, sim, o professor que propicia o encantamento do aluno em relação à disciplina a qual está ministrando! Entendemos que o encantamento ofertado pelos professores de Geografia se dá, em um primeiro momento, pelo seu encantamento em relação a esta ciência que tanto nos apaixona!

Gráfico 1 - Influência da Geografia

\section{Influência na Geografia}

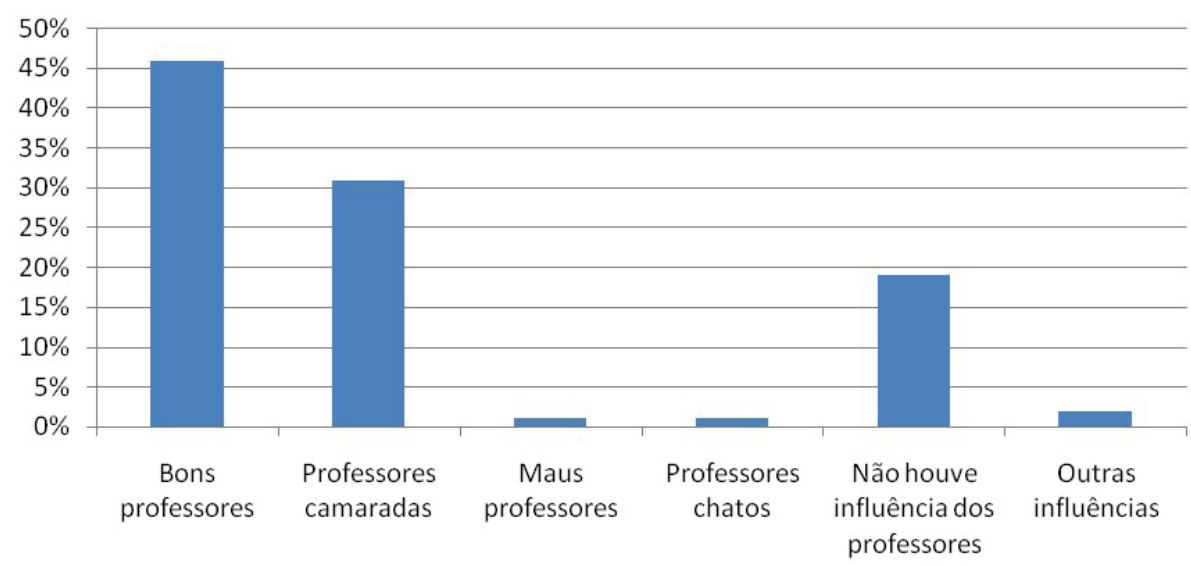

Fonte: Elaborado pelo autor.

Ora, em meu caso e em muitos dos casos que conhecemos, a escolha pelo curso de Geografia se deu justamente por esse encantamento, por gostar muito da Geografia e, de fato, passamos isto aos nossos alunos. O que pesa (e daí afirmamos derivar tantas pesquisas em ensino de Geografia - como este estudo) é que, por vezes, trata-se de uma paixão individual pela ciência geográfica, que pouco ou nada é compartilhada com alunos por meio de nossas práticas docentes!

Se formos realizar um apanhado geral e baseado em uma metodologia simples, porém, muito clara, das percepções dos alunos em relação ao ensino de Geografia e de como percebem esta ciência, encontraremos dados que, de fato, refletem dois aspectos: a) a realidade de muitas escolas brasileiras - públicas e privadas; e b) o senso comum das pessoas em relação à Geografia, enquanto ciência presente no âmbito escolar. Pois bem, provocamos nossos jovens-sujeitos da pesquisa a escreverem as três primeiras palavras que lhes viessem à cabeça quando escutavam a palavra "Geografia”. Observemos o gráfico de respostas a seguir. 
Gráfico 2 - Três palavras que lembram Geografia

\section{3 palavras que lembram Geografia}

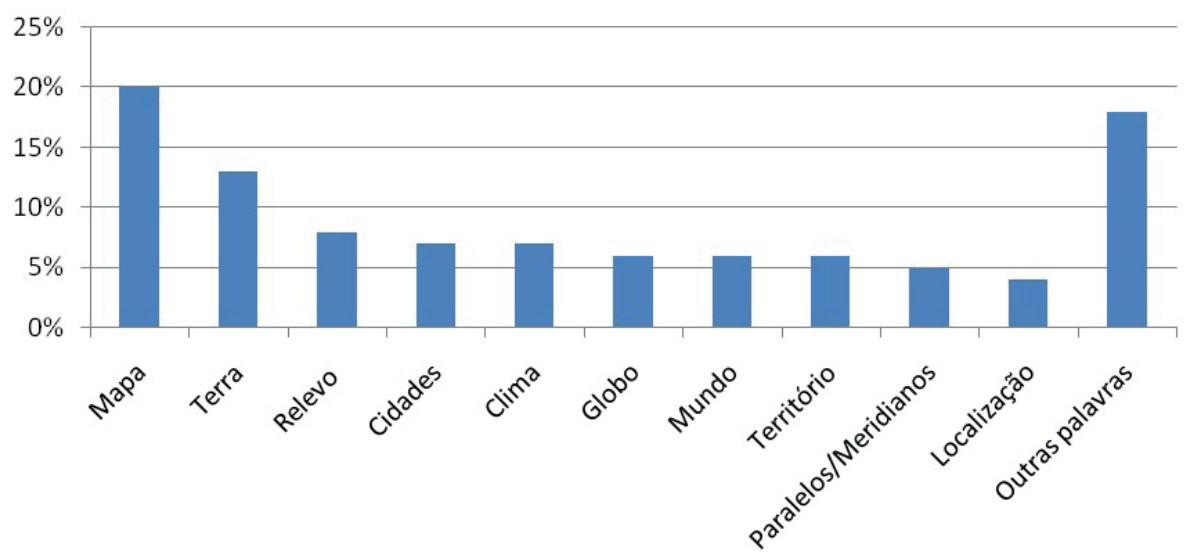

Fonte: Elaborado pelo autor.

Preferimos classificar as respostas dos entrevistados desta forma, a dar clareza ao leitor das palavras mais repetidas que, em nosso entendimento, formam o sensopadrão-comum da amostra entrevistada em relação à Geografia.

Não nos surpreendeu, de forma alguma, que a palavra mais citada seria Mapa! Ora: o que seria da Geografia sem mapas? Não queremos entrar no mérito da resposta que acabamos de elencar, já que desviaríamos o foco deste trabalho por longas páginas. Mas há que se admitir que a Geografia esteja - intrinsecamente - relacionada ao estudo do mapa, do globo, da Terra. Esse é um pensamento que herdamos de nossos pais, avós e bisavós, e que, por mais que tentemos formar alunos de ensino fundamental e médio com uma visão mais crítica da realidade e do espaço geográfico, dificilmente nos desligaremos dessas visões em relação à Geografia. E, de fato, não podemos nos desligar! Afinal, o mapa, por exemplo, é um instrumento de espacialização de dados importantes (por exemplo: IDH, violência urbana, fome etc.).

O que estamos postulando aqui é que deixemos de ser a Geografia única dos topônimos - aquela Geografia que apenas dá nome aos espaços ou que ainda tem seus nomes próprios, como o mapa, por exemplo - e que passemos a ser a Geografia real, aquela que possa levar os alunos a uma dimensão crítica e atuante em suas realidades. Mas como? Acreditamos que o primeiro momento é este: conhecer o aluno, o jovem, que está na minha frente! Para depois pensarmos na Geografia ensinada-aprendida por esses jovens!

Concordo com Kaercher (2014, p. 230) quando afirma que não podemos cair no automatismo da Geografia: 
Se o professor não fizer as relações entre o de que está tratando e a Geografia o aluno tende a se dispersar. Corolário: Geografia fala de tudo, Revista de variedades. Leve. Leva a uma aprendizagem pouco eficaz. Há pouco o que pensar nas aulas de Geografia.

Percebemos essa Geografia "leve", quando observamos que mais da metade das palavras citadas pelos entrevistados inferem-se em temas físicos, pontuais e introdutórios da ciência geográfica, como: mapa (por supuesto!), Terra, relevo, clima, paralelos, meridianos, localização... Mas, nos falta algo, não?! Onde está a dita Geografia Crítica? Por que não aparecem palavras como sociedade, política, ambiente, cidade $\mathrm{X}$ campo, segurança pública, transporte, mobilidade urbana, código penal, Nações Unidas, Amazônia, ...? Por que, se passados mais de três décadas após a "revolução" na Geografia brasileira, o que nos vem ainda é o tradicional, o físico, o emblemático da Geografia? Encontro amparo (e apoio emocional!) em Kaercher (2014, p. 231) quando afirma que: "[...] a Geografia, independentemente de chamála de 'crítica' [...] possa ajudar os alunos a olharem o mundo em que vivem de forma mais plural, complexa, contraditória e dinâmica. Sim, de forma crítica”.

Aísim podemos afirmar que não é apenas de temas físicos, por exemplo, que vive a Geografia escolar! Na sociedade contemporânea existem temas tão emergentes que podem justamente ser tratados de forma plural, complexa, contraditória e dinâmica, sem deixar de seguir os currículos! E que envolvem, diretamente, as vivências desses sujeitos jovens, como já apresentamos em tópicos anteriores a este, neste texto, como, por exemplo, as relações dos jovens com seus estudos.

Fica evidente que a Geografia tem se mantido esta revista de variedades, quando observamos as palavras mais relacionadas com a ciência (mapa, Terra, relevo, cidades, clima, ...) e, ainda mais, quando verificamos as principais utilidades da Geografia para os jovens, no momento em que questionamos os entrevistados: Qual é a utilidade da Geografia para você? Obtivemos as seguintes respostas:
a) conhecer mais sobre o mundo: $45 \%$;
b) saber se localizar: $24 \%$;
c) saber sobre os outros países: $11 \%$;
d) localizar países: $4 \%$;
e) saber fusos horários: $4 \%$;
f) outros (várias utilidades citadas): $12 \%$.

A partir dessas observações interpretamos, num primeiro momento, que os alunos que veem na Geografia a potencialidade de conhecer mais sobre o mundo (expressiva quantidade de respostas) estão, justamente, relacionando a ciência geográfica com esta temática livre, que fala de tudo (do mundo), mas com pouca aprendizagem efetiva. Veja bem, caro leitor, não estamos afirmando que conhecer mais 
sobre o mundo não seja aprendizagem (porque de fato o é!), mas o que queremos destacar aqui é a fragilidade com que os entrevistados percebem a Geografia escolar:

Depois de percorrermos cerca de três milhas, chegamos a uma espécie de edifício
comprido, construído de troncos fincados no chăo e entrelaçados; o teto baixo e
coberto de palha. Comecei a sentir-me então algum tanto confortado e tomei de
alguns brinquedos, que trazem habitualmente os viajantes a fim de presentearem
os indígenas selvagens da América, e de outras partes [...]. (SWIFT, 1952, p. 193).

Sim, caro leitor, a primeira sensação, quando constatamos que para $45 \%$ dos jovens a Geografia é unicamente conhecer mais sobre o mundo, é que somos os contadores das histórias de Gulliver, ao desbravar e conhecer novos espaços, relatando, minuciosamente, estes espaços viajados, conhecidos e explorados. Rico! Sim, isto é muito rico! O que ocorre é que analisamos essa resposta sob a égide de um professor-pesquisador que entende que a Geografia escolar deva ser muito mais do que apenas a descrição toponímia - dos espaços! Não nos serve nem nos basta apenas "conhecer mais sobre o mundo", se não damos valor/importância/criticidade àquilo que está a nossa frente: nossa cidade, por exemplo!

Da mesma forma, questionamos as outras respostas mais verificadas: saber se localizar, saber sobre os outros países, localizar países, saber fusos horários. É óbvio que, para nós, geógrafos (professores e bacharéis), nos parece muito claro o porquê de estudar estes temas da Geografia. É importante saber se localizar sim! É importante saber onde estão os países no mundo sim! Mas, é importante só porque nos diz respeito? Como essa importância pode ser reflexionada com os alunos? Se soubermos responder estas perguntas, já temos muito assunto para discutir com os jovens-alunos, a importância daquilo que fazemos em nossas aulas!

Questionamos também os alunos para nos relatarem como fazem para aprender ou para estudar Geografia. As duas respostas mais citadas (assistindo às aulas $-45 \%$ e lendo o livro didático - 30\%) já nos eram esperadas, pois se trata do óbvio! O que de fato nos surpreendeu foi a terceira resposta apresentada: $20 \%$ dos entrevistados afirmaram que, para aprender ou estudar Geografia, utilizam vídeoaulas! Claro, reflexo daquilo que já afirmamos no ponto anterior, quando tratamos do jovem e sua conectividade (em tempos online). Basta realizarmos uma breve pesquisa no website YouTube com o texto "vídeoaula geografia", que encontraremos mais de 13.000 (treze mil!) vídeos relacionados com o tema pesquisado.

Parece-nos muito claro que a maior parte - se não a totalidade - das vídeoaulas apresentadas no YouTube sejam destinadas à preparação de alunos para provas de vestibular, para o ENEM ou ainda para concursos públicos em geral. Percebo, 
Figura 1 - Exemplo de Vídeoaula no YouTube

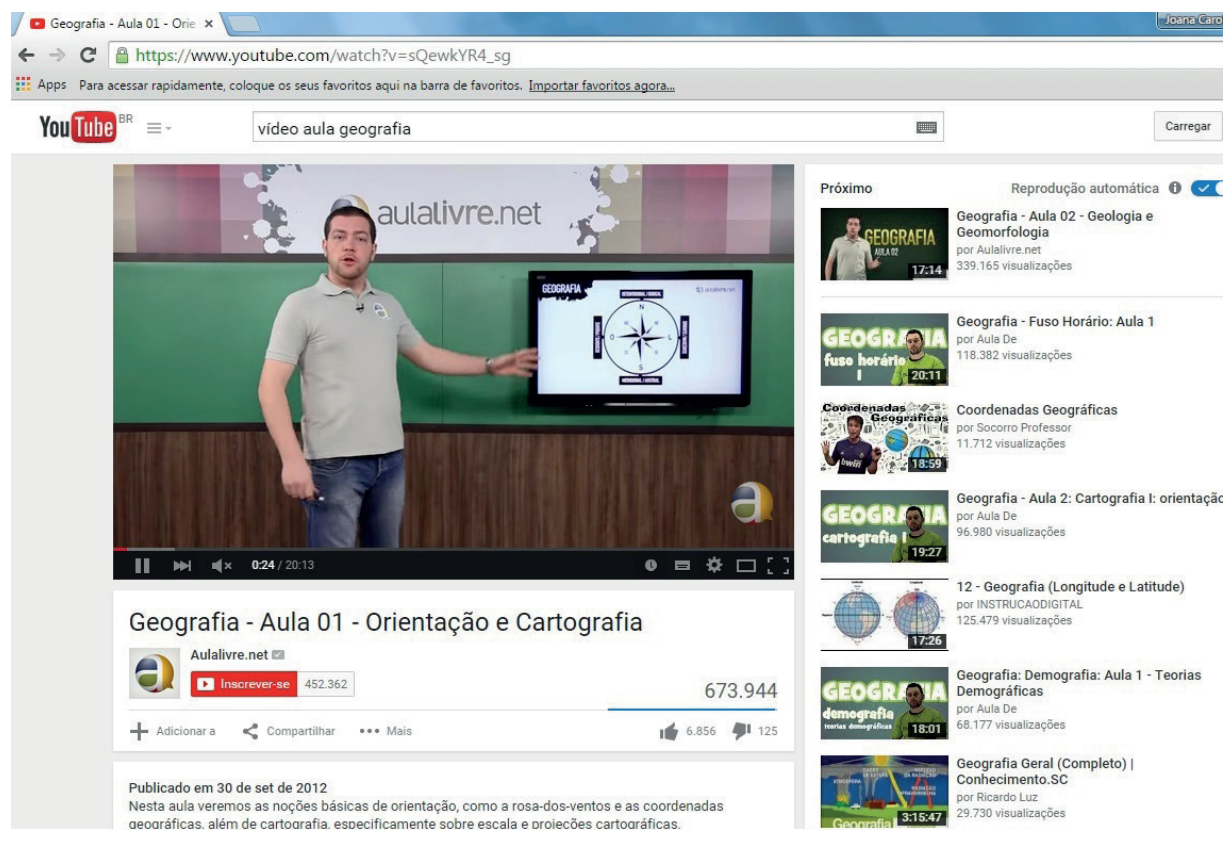

Fonte: YouTube (2015).

em meu cotidiano docente, que muitos alunos se utilizam deste instrumento de aprendizagem, se assim podemos classificá-lo, como forma de revisão - urgente para quando da aplicação de provas ou atividades avaliativas.

O dado que nos apareceu durante nossa análise e tabulação das respostas do questionário de pesquisa nos assombrou na medida em que perguntamos como fazem para aprender ou estudar Geografia e que, em nosso entendimento, a presença - real - do professor e as possibilidades de se abrir uma discussão - real - sobre o que está sendo tratado é muito mais rica, fiel e satisfatória do que o simples "despejar" de conteúdos que acontece no âmbito das aulas virtuais supracitadas.

Relacionado a este tema questionado, perguntamos aos jovens entrevistados onde mais, além da sala de aula, é possível aprender Geografia, e obtivemos as seguintes respostas, apresentadas no gráfico 3 .

A resposta mais elencada (documentários de televisão) sugere-nos que ainda persiste a visão da Geografia como "revista de variedades", já apresentada neste capítulo. Globo Repórter, National Geografic, Discovery Channel são exemplos de onde o aluno-jovem encontra "Geografia”.

No YouTube, como já apresentado, o aluno cita que é possível aprender Geografia igualmente, e, pelo visto, uma Geografia repleta de "decorebas" e macetes para o ingresso, pelo vestibular, em instituições. 
Gráfico 3 - Onde mais é possível aprender Geografia

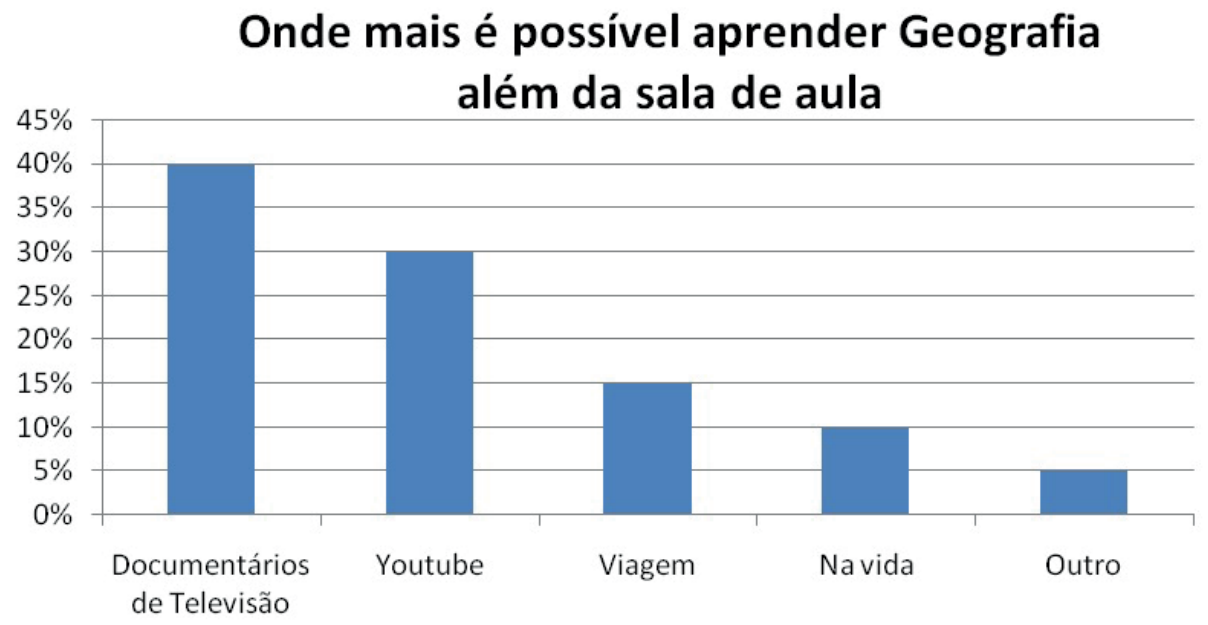

Fonte: Elaborado pelo autor.

O terceiro dado analisado, através de viagens, nos é de interessante análise e, para isto, questionamos os alunos sobre: qual foi a viagem mais longa que tu fizeste?

O fato de $14 \%$ dos alunos responderem que nunca viajaram (sequer saíram de Porto Alegre) nos faz refletir sob alguns aspectos: a) a situação econômica de muitas das famílias dos entrevistados, como já apresentado no perfil geral dos sujeitos da análise; b) a necessidade da realização de saídas de estudos com os alunos, que, de alguma forma, mesmo dentro de sua cidade, podem expandir seus horizontes.

Uma parcela de $22 \%$ já viajou para o interior do Estado do RS, afirmando que foram visitar familiares que moram nestas regiões. Já 35\%, a maioria dos sujeitos da amostra de pesquisa, inferiu ter viajado para o Estado vizinho, Santa Catarina, e, mais especificamente, para a região das praias, litoral muito cobiçado em épocas de férias e veraneio.

Cerca de $30 \%$ dos alunos declararam ter saído para outros estados (16\%) ou exterior - Cone Sul da América do Sul (14\%). Tal quadro é típico de escola pública. Não nos surpreenderia, caso a pesquisa fosse realizada em uma escola privada, cujos alunos possuam alto padrão financeiro, que a quase totalidade dos mesmos já tivessem viajado para o exterior. 
Gráfico 4 - Já viajou?

\section{Já viajou?}

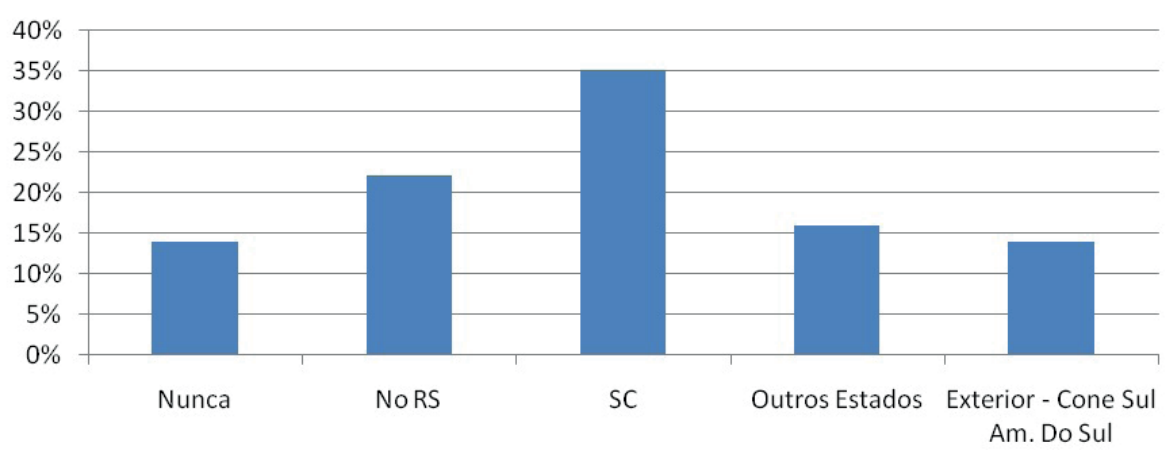

Fonte: Elaborado pelo autor.

\section{De jovens e seu direito à cidade}

Por fim, no que se refere ao aproveitamento da Geografia nas vivências de nossos jovens-alunos-sujeitos-entrevistados, questionamos sobre os espaços de Porto Alegre (sua cidade) que mais gostam de frequentar e nos deparamos com as seguintes respostas, conforme analisamos no gráfico 5 .

Dos doze espaços inferidos nessa pergunta, gostaríamos de dar destaque aos dois primeiros, quando classificados por ordem de aparecimento: shoppings (Praia de Belas, o mais elencado) e o Parque Farroupilha (a conhecida Redenção). Escolhemos falar desses dois espaços por serem, de certa forma, um resumo das vivências juvenis na cidade, para além de sua própria casa, sua escola e seu trabalho, quando o há.

Falar em shopping é, em um primeiro momento, marcar a necessidade de um sistema capitalista, de pensar, arquitetar, construir e manter "templos de compras". Não quero aqui ficar criticando o sistema, até porque vivo nele, frequento shoppings e, superficialmente, não enxergo tantos problemas que mereçam destaque neste tipo de trabalho. $O$ fato é que o shopping se tornou um espaço de vivência não só juvenil, mas também destes que são os mais assíduos frequentadores destes espaços. Em Porto Alegre, o Shopping Praia de Belas é o mais frequentado pelos alunos-sujeitos da pesquisa, pois é um entre-caminho no trajeto entre suas casas, a escolas e seus locais de trabalho (como será explicitado e visualizado no próximo subcapítulo).

Criado em 1992, o Praia de Belas foi um dos primeiros shoppings da capital gaúcha, juntamente com o Iguatemi, o qual atualmente é o administrador deste shopping. Recentemente passou por obras de ampliação, formatando o espaço em 
Gráfico 5 - Espaços de Porto Alegre

\section{Espaços de POA}

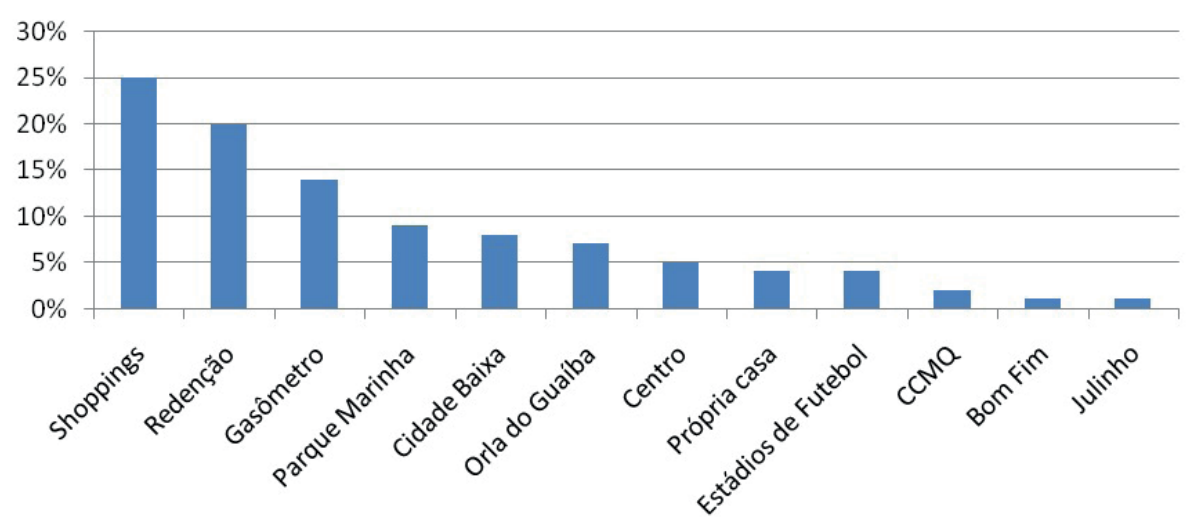

Fonte: Elaborado pelo autor.

Figura 2 - Shopping Praia de Belas

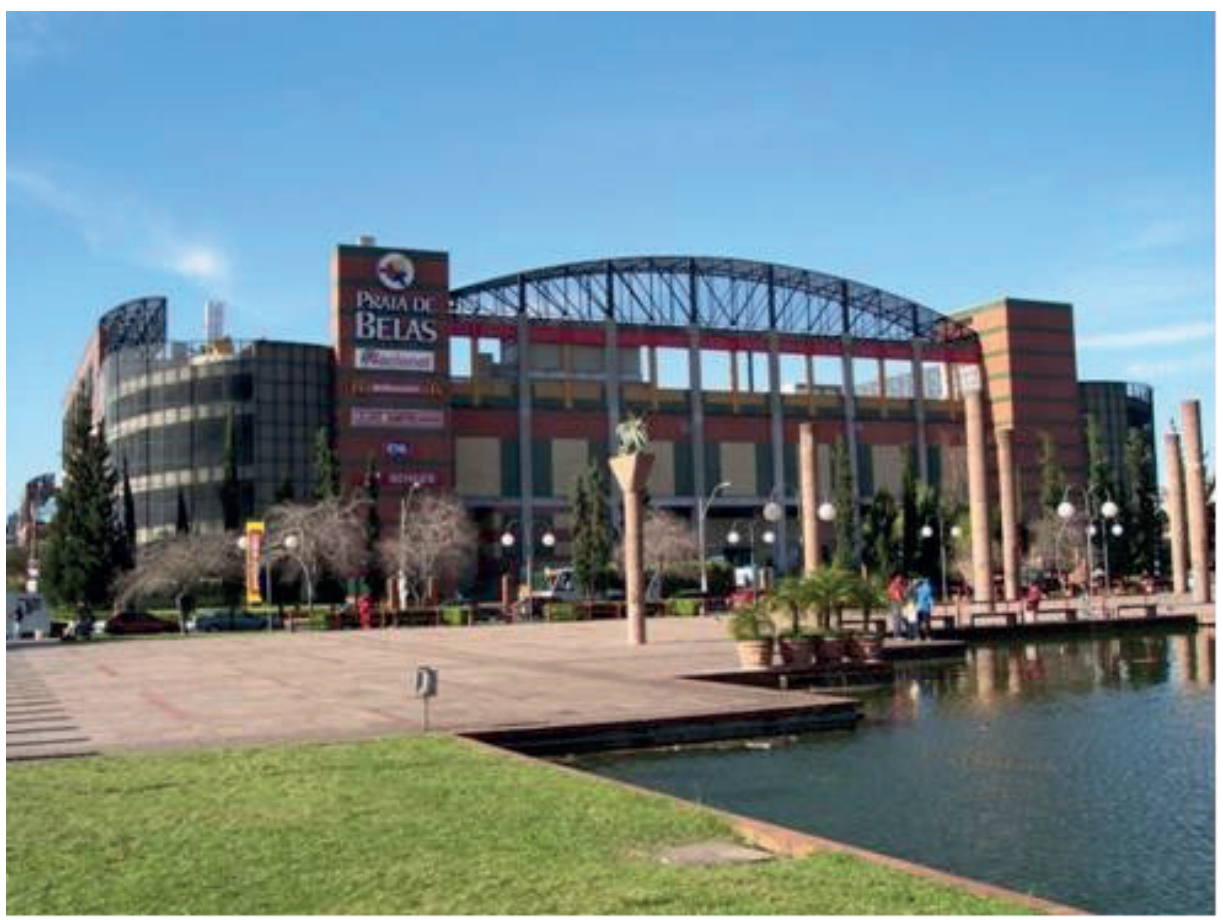

Fonte: Praia de Belas Shopping 
três andares de lojas e com a construção de um prédio externo de estacionamento e de uma torre comercial ligada ao prédio principal do shopping.

O shopping, nesse sentido, torna-se espaço de sociabilização desses jovens, na medida em que o frequentam e que nele realizam performances sociais, como a do ultimamente conhecido "rolezinho". Esse é o termo designado para a junção de jovens em um shopping, que muitas vezes é agendada via online (Facebook, por exemplo). A seguir, podemos observar uma imagem de um "rolezinho", que esclarece nossa visão sobre a proposta.

Ao chegar neste ponto do texto o leitor poderia se perguntar: mas o que há de Geografia nisto? A resposta é imediata: tudo! Em primeiro lugar cabe ressaltar que, nesta performance social do "rolezinho", o jovem territorializa o espaço do shopping, muitas vezes causando indisposições com a segurança e os lojistas. Há o recente caso de outro shopping, em Porto Alegre, que, nos finais de semana, barrou a entrada de menores de 16 anos se não estivessem acompanhados dos pais ou responsáveis. Sobre o ato de o jovem territorializar o espaço do shopping, se faz mais do que necessário retomar o conceito de território proposto por Haesbaert (2004, p. 1), quando afirma que

[...] território, assim, em qualquer acepção, tem a ver com poder, mas não apenas ao tradicional "poder político". Ele diz respeito tanto ao poder no sentido mais concreto, de dominação, quanto ao poder no sentido mais simbólico, de apropriação.

Nesse sentido, percebemos que esses jovens, ao estarem em um espaço da cidade, estão exercitando uma tentativa de apropriação deste espaço, no caso, um shopping. Quão

Figura 3 - Formação do "rolezinho" em um shopping

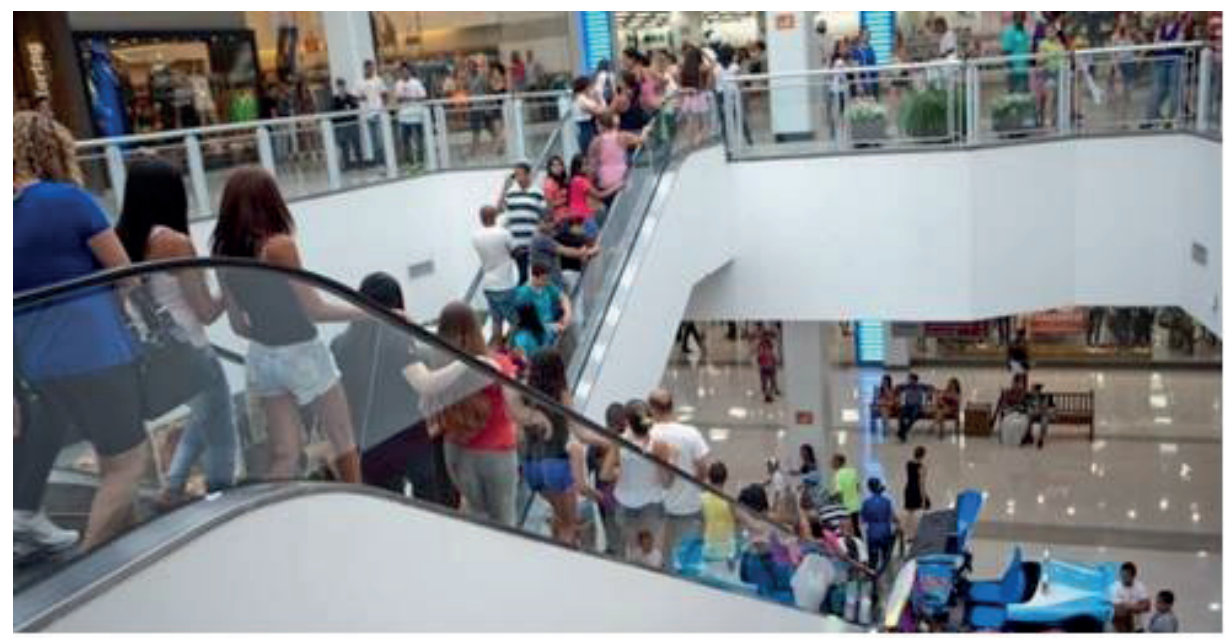

Fonte: Portal UOL de Notícias (2015). 
rico isto é para a Geografia! Particularmente, busco explorar estas discussões em minhas aulas, de como estas vivências de meus alunos (jovens contemporâneos) formam parte, por exemplo, da materialidade de conceitos geográficos, conceitos estes que estão sendo cobrados cada vez mais em avaliações externas, como o ENEM.

Outro espaço vivenciado pelos alunos-jovens da amostra da pesquisa é o Parque Farroupilha (Redenção).

Espaço da antiga Vila de Porto Alegre, o Parque Farroupilha já foi área de Várzea, que ficava fora dos muros e dos portões da cidade. Espaço de criação de gado, de embates da Revolução Farroupilha, de comemorações - precoces - da abolição da escravatura, apenas em 1927 foi declarado parque e, muito depois, em 1997, tombado pelo Município de Porto Alegre como patrimônio histórico-cultural da cidade.

O Parque Farroupilha é um espaço de convivência e manifestações das culturas juvenis presentes em Porto Alegre. Não nos surpreendeu essa resposta no questionário de pesquisa, quando perguntamos sobre os espaços da cidade que são utilizados/ ocupados/vividos pelos jovens urbanos contemporâneos.

Pereira (2011) já nos aclarava da importância do estudo das vivências do jovem urbano, justamente no Parque Farroupilha, espaço de pesquisa da Tese intitulada

Figura 4 - Parque Farroupilha

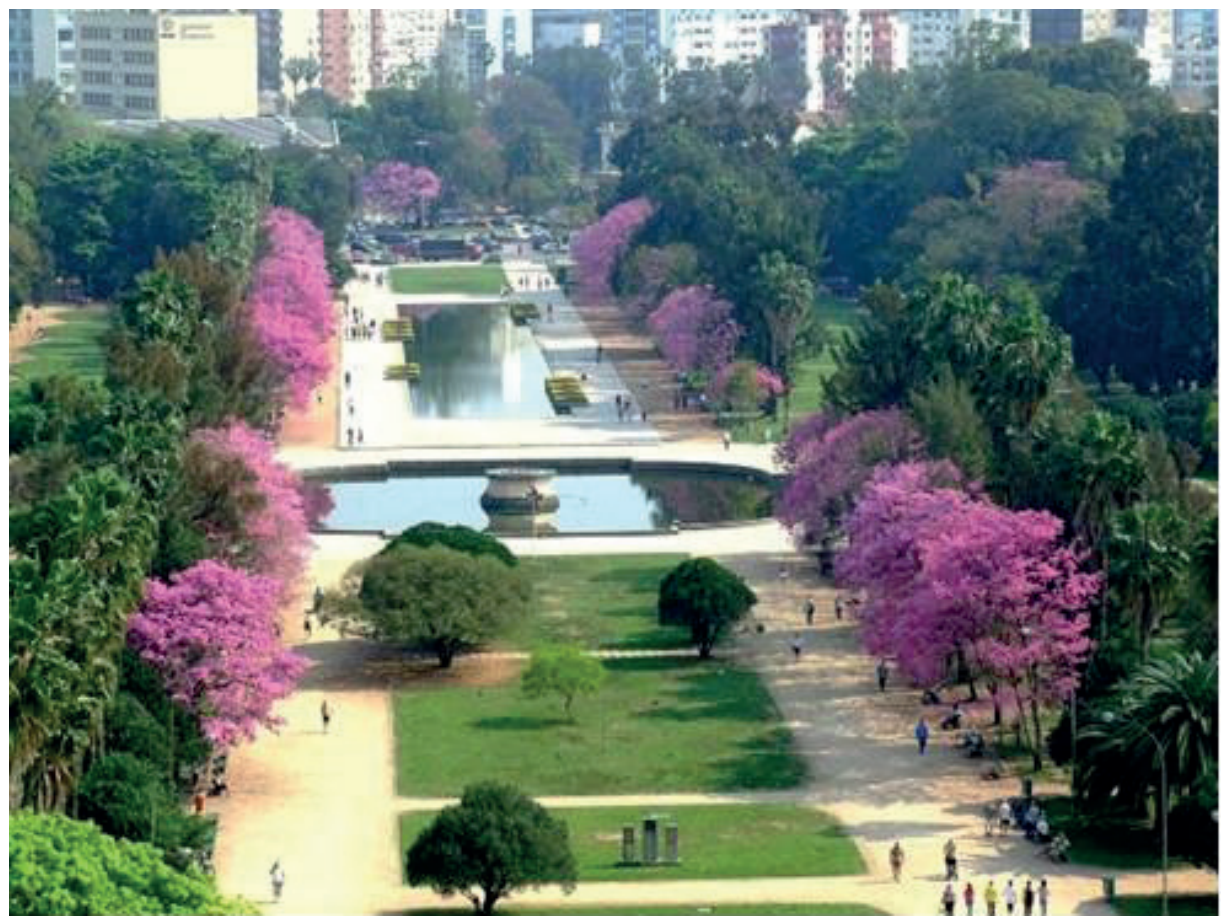

Fonte: ClicRBS (2015). 
"Domingo no Parque: notas sobre a experiência do ser jovem na contemporaneidade". A autora destaca de maneira clara as vivências desses jovens e das formas com que ocupam o Parque Farroupilha nos mais variados moldes, por exemplo:
a) vivências semanais de grupos (tribos);
b) a exibição dos corpos e os expectadores que os estão assistindo;
c) a diversidade sexual e a "pegação" no parque;
d) a diversidade musical e o encontro dos jovens;
e) os jovens que se embriagam com vinho;
f) a performance de grupos homossexuais;
g) a performance de várias tribos;
h) os eventos que ali acontecem, como a parada gay.

E a Geografia? Se tivermos grupos juvenis oriundos de diferentes tribos, ocupando um único espaço (Parque Farroupilha), nos parece claro que volta à tona o conceito de território e territorialidades, no qual os jovens vão exercer suas noções de poder sobre os espaços. Interessante como Pereira (2011) coloca-nos a refletir sobre o quão suscetível e dinâmica são essas manchas de jovens de diferentes grupos que se movem nos espaços do Parque durante um domingo, por exemplo. Se isto não for Geografia, há que se rever então o que ela de fato é.

Figura 5 - Um domingo qualquer no Parque Farroupilha

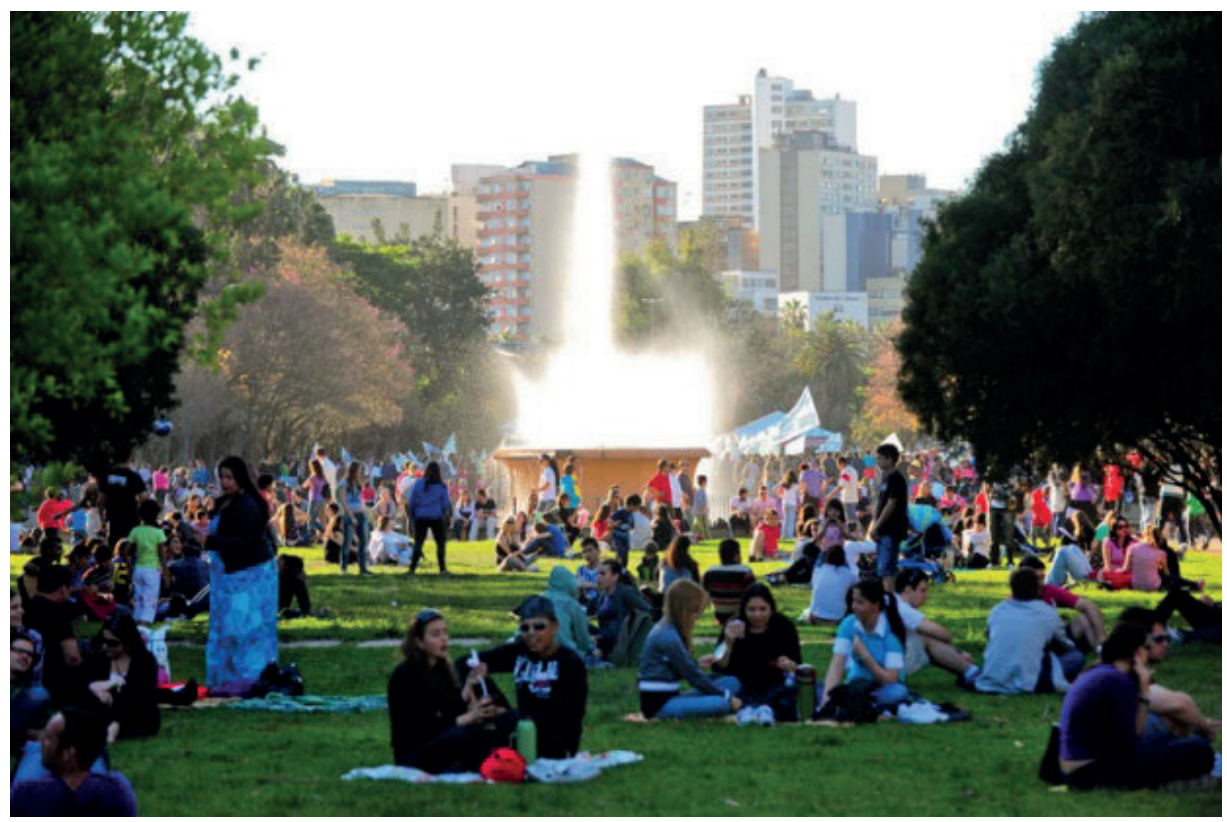

Fonte: Clic RBS (2015). 
Veja bem, caro leitor, o que realizamos aqui foi uma pequena amostra do quão variado é o universo de nossos jovens-alunos, quando colocamos suas práticas sociais relacionadas a alguns dos conceitos da Geografia e o quão ricas seriam nossas aulas se utilizássemos estas vivências para discutir temas e formar conceitos nestes jovens, ademais, formar cidadãos que saibam realizar leituras - críticas, por que não - do mundo no qual estão inseridos.

\section{Para novas leituras de jovens e de geografia escolar}

Pareceu-nos muito claro que as relações efetuadas entre esse jovem contemporâneo e o ensino de Geografia estão ligadas aos temas físicos da ciência. Quando os questionamos sobre a "serventia da Geografia", nos são oferecidas como respostas às temáticas físicas (duras) da ciência geográfica, como localizar países ou saber fusos horários, por exemplo. Se perguntarmos ainda quais são as palavras que mais lembram a Geografia, os mesmos inferem, em sua maioria, em palavras da ordem da Geografia física.

Essa constatação nos faz refletir sobre como vem sendo dada a condução de nossas aulas e sobre como vem sendo pensados os currículos escolares e os programas de ensino. Vejamos alguns questionamentos importantes:

a) sobre nossas aulas:

- Estamos dando a verdadeira importância ao conceito de Espaço Geográfico e suas relações entre os temas sociais e naturais?

- Estamos contextualizando as realidades locais dos alunos, de maneira a termos uma abordagem das diferentes escalas geográficas, partindo do local e chegando ao global (e vice-versa)?

- Estamos tendo espaço para discutir com os alunos as temáticas dos movimentos sociais, das cidades, das populações, de maneira com que eles se sintam participantes destas questões?

- Não estaríamos frisando em demasia o tema físico da Geografia, uma vez que, no imaginário popular, este tema dá mais "validade" à ciência geográfica? b) Sobre os currículos escolares e os programas de ensino:

- Estamos balanceando as temáticas físicas com as temáticas humanas da Geografia, ao planejarmos nossos planos de ensino?

- Estamos conseguindo efetuar a devida defesa da permanência da Geografia nas grades de currículos, quando sabemos que em muitas escolas não há mais Geografia nos três anos do ensino médio?

- Estamos cientes das propostas dos órgãos competentes (Ministério e Secretarias de Educação) no que diz respeito ao ensino de Geografia? 
Caro leitor, são muitas as perguntas! Encontramos respostas para elas? Nesse sentido é que nos referimos ao afirmar que a busca por responder uma pergunta nos abre espaço para outras tão urgentes quanto a primeira.

Acredito ser importante lembrar, neste espaço, Meirieu (2006, p.25), em sua "Carta a um Jovem Professor", sobre uma visão importante do professor: "Não há nada de extraordinário, então, em considerarmos nosso ofício como um meio de possibilitar a outros que vivam a alegria das descobertas que nós próprios vivemos".

E, ainda, uma visão importante sobre o conhecimento, ainda conforme as palavras do autor (2006, p.19): "O professor deve possibilitar a cada aluno confrontarse com um saber que o ultrapassa e, ao mesmo tempo, fornecer-lhe a ajuda necessária para se aproximar deste saber".

Avante, companheiros! Há muito trabalho a ser feito! Mais pesquisas, mais aulas, mais jovens e mais reflexões virão!

\section{Referências}

CACCIA-BAVA, A.; COSTA, D. I. P. O lugar dos jovens na história brasileira. In: CACCIABAVA, A.; PAMPOLS, C. F; CANGAS, Y. (Orgs). Jovens na América Latina. São Paulo: Escrituras, 2004. p. 63-114.

CLIC RBS. Almanaque Gaúcho. Disponível em: <http://wp.clicrbs.com.br/almanaquegaucho/ files/2012/03/julinhoricardoduarte12042002.jpg>. Acesso em: 20 abr. 2015.

HAESBAERT, R. Dos múltiplos territórios à multiterritorialidade. Revista do PET, Porto Alegre, 2004. Diponivel em: <http://www.ufrgs.br/petgea/Artigo/rh.pdf>. Acesso em: 12 abr. 2015.

KAERCHER, N. A. Se a Geografia escolar é um pastel de vento o gato come a geografia crítica. Porto Alegre: Evangraf, 2014.

MEIRIEU, P. Carta a um jovem professor. Porto Alegre: Artmed, 2006.

PAIS, J. M. Culturas juvenis. Lisboa: Imprensa Nacional-Casa da Moeda, 2003.

PEREIRA, A. S. Domingo no Parque: notas sobre a experiência de ser jovem na contemporaneidade. 2011. Tese. (Doutorado em Educação) - Faculdade de Educaçao, Universidade Federal do Rio Grande do Sul, Porto Alegre.

PORTAL UOL. Disponível em: <http://imguol.com/c/noticias/2014/01/ 13/11jan2014--usuarios-do-facebook-marcaram-um-rolezinho-no-shopping-itaquera-na-tarde-deste-sabado11-o-shopping-reforcou-a-seguranca-e-pediu-apoio-a-policia-militar-lojas-fecharam-as-portas1389627068680_956x500.jpg>. Acesso em: 20 abr. 2015.

SWIFT, J. Viagens de Gulliver. Rio de Janeiro: Globo, 1952.

YOUTUBE. Geografia - Aula 01 - Orientação e Cartografia. Disponível em: <https://www. youtube.com/watch?v=sQewkYR4_sg>. Acesso em: 20 abr. 2015. 